\title{
Analysis of Different Containment Models for IRIS Small Break LOCA, using GOTHIC and RELAP5 Codes
}

\author{
Davide Papini, Antonio Cammi, Marco Ricotti \\ Politecnico di Milano - Department of Energy \\ Nuclear Division-CeSNEF \\ Via La Masa, 34 - 20156 Milano, Italy \\ davide.papini@mail.polimi.it \\ Davor Grgić \\ University of Zagreb, Faculty of Electrical Engineering and Computing \\ Department of Power Systems \\ Unska, 3 - 10000 Zagreb, Croatia \\ davor.grgic@fer.hr
}

\begin{abstract}
Advanced nuclear water reactors rely on containment behaviour in realization of some of their passive safety functions. Steam condensation on containment walls, where noncondensable gas effects are significant, is an important feature of the new passive containment concepts, like the AP600/1000 ones.

In this work IRIS reactor was taken as reference, and the relevant condensation phenomena involved within its containment were investigated with different computational tools. In particular, IRIS containment response to a Small Break LOCA (SBLOCA) was calculated with GOTHIC and RELAP5 codes. IRIS containment drywell was modelled with RELAP according to a sliced approach, based on the two-pipe-with-junction concept, while it was simulated with GOTHIC testing several modelling options, regarding both heat transfer correlations and volume and thermal structure nodalization. The influence on containment behaviour prediction was investigated in terms of drywell temperature and pressure response, Heat Transfer Coefficient (HTC) and steam volume fraction distribution, and internal recirculating mass flowrate. The objective of the paper is to compare the capability of the two codes in modelling of the same postulated accident, thus to check the results obtained with RELAP5, when applied in a situation not covered by its validation matrix.

The option to include or not droplets in fluid mass flow discharged to the containment was the most influencing parameter for GOTHIC simulations. Despite some drawbacks, due e.g. to a marked overestimation of internal natural recirculation, RELAP confirmed its capability to satisfactorily model the IRIS containment.
\end{abstract}

\section{INTRODUCTION}

The IRIS reactor [1] features a primary system fully integrated within a single pressure vessel, which eliminates by-design the possibility of large releases of primary coolant. The main design basis events deal consequently with Small Break LOCA accidents. The demonstration of the reactor capability to successfully respond to the various initiating events requires a deep knowledge of all the thermalhydraulic phenomena involved in each postulated 
sequence and the availability of appropriate computer tools, in position to accomplish an integrated approach analysis to the whole reactor system (including containment).

Five break cases have been envisaged to confirm the capability of IRIS plant in mitigating the consequences of a SBLOCA event, in particular thanks to the possibility of maintaining the Reactor Coolant System (RCS) inventory without the necessity of high and low pressure injection systems. Among these breaks, DVI (Direct Vessel Injection) line break has been selected for initial analysis due to its potential to maximise water inventory depletion.

The present work is a contribution to the activities in progress in the frame of the transient analyses comparing IRIS plant response to the mentioned break with that of its scaled integral test facility SPES3 [2], designed by SIET company to simulate the accidental sequences involving IRIS primary, secondary and containment systems. Simulations of the DVI-SBLOCA are being performed with the RELAP5/GOTHIC coupled model [3] developed by University of Zagreb as relates IRIS plant, and with the RELAP5 integral model [2] of the facility developed by SIET to support different stages of the SPES3 design.

Objective of this paper is to discuss several containment models and to check the capability of RELAP code of simulating thermalhydraulic transients in large volumes, generally treated with the dedicated multi-dimensional software package GOTHIC (Generation Of Thermal-Hydraulic Information for Containments). Heat structure modelling and available heat transfer correlations have been stressed in the analysis. A simplified model of IRIS drywell has been developed both in GOTHIC and in RELAP; temperature and pressure transients have been assessed in response to the same boundary conditions (mass and energy terms calculated for the DVI Break by complete IRIS RELAP/GOTHIC model) and with the same amount of heat structures (in IRIS conditions). When comparing results of IRIS calculations using coupled RELAP/GOTHIC code and SPES3 calculations using RELAP code some differences were found in variables being selected as representative for most important phenomena. The differences can be related to the limitations of performed scaling process (1:100 volume ratio and full elevations) and to the selected modelling and calculational capabilities of used computer codes. A key point of the work is to identify what is level of distortions possible between RELAP and GOTHIC results when modelling IRIS containment drywell, taking into account both, selected discretizations appropriate for each code and available HTC correlations. As a second goal, the most accurate GOTHIC containment modelling approach, to be used in realistic IRIS transient analyses, should be selected. To the aim, several physical model options and heat transfer correlations have been tested, estimating their impact on the system response.

A similar benchmark of different codes for containment applications can be found in [4], where anyhow no heat transfer was assumed from the containment atmosphere to the containment structures and to the external environment.

\section{CONDENSATION MODELLING FOR CONTAINMENT APPLICATIONS}

This Section is dedicated to the main phenomenological issues concerning steam condensation on containment walls and to the different approaches available in literature for its modelling.

The key parameter influencing the condensation of the steam released within the containment atmosphere is composition and concentration of non-condensable gas. Large amounts of air (or nitrogen), present in normal operation conditions inside the reactor containment, create an additional thermal resistance and worsen significantly the condensation process by reducing interface saturation temperature at steam partial pressure, hence the temperature difference with the wall which drives the process [5]. 
Two are basically the kinds of approach available for taking duly into account the noncondensible effects on steam condensation inside a containment:

- empirical correlations estimating condensation HTC dependence on non-condensable gas mass fraction;

- more mechanistic models based on the analogy between heat and mass transfer.

Several recent works [6][7] investigated the phenomenon relying on analogy-based models, which consider effects like suction, film turbulence and mist formation that are encountered in case of strong temperature gradients across the wall, normally externally cooled, as it is for the AP600/1000 containment [6]. Actually, all the analogy-based models tend to underestimate experimental results without empirical correction factors to account for the mentioned effects. Thus, in addition to the consideration that IRIS containment wall is not externally cooled, it seemed more suitable to utilize in the study condensation correlations based on experimental data, like Uchida correlation.

Four direct condensation options, not establishing the interface phenomena typical of diffusion layer models, are available in the heat transfer package of GOTHIC code [8]:

- Uchida correlation;

- Gido-Koestel correlation;

- maximum of Uchida and Gido-Koestel correlations;

- modified Uchida correlation.

Amongst them, the Uchida has been the preferred one to be selected in the analyses. Extensively used in the nuclear industry to predict condensation rates inside containment structures, Uchida correlation is based on experimental data collected with a constant volume vessel initially filled with 1 atm of non-condensable gas. Heat removal rates are instead significantly underpredicted for bulk gas pressure above $1 \mathrm{~atm}$ and overpredicted for bulk gas pressure under $1 \mathrm{~atm}$. Its validity is limited to the range $11.36-1578.48 \mathrm{~W} / \mathrm{m}^{2} \mathrm{~K}$.

Different formulations have been anyway found in literature (as well as in GOTHIC heat transfer package) for Uchida correlation. HTC can be expressed as a function of noncondensable gas mass fraction $W$ [6], or else as a function of the ratio of non-condensable bulk density $\rho_{g b}$ to vapour bulk density $\rho_{v b}$ [8][9]. Both formulations, listed in Table 1, are equivalent, except for the numerical coefficient depending on the gas composition and on selected HTC units.

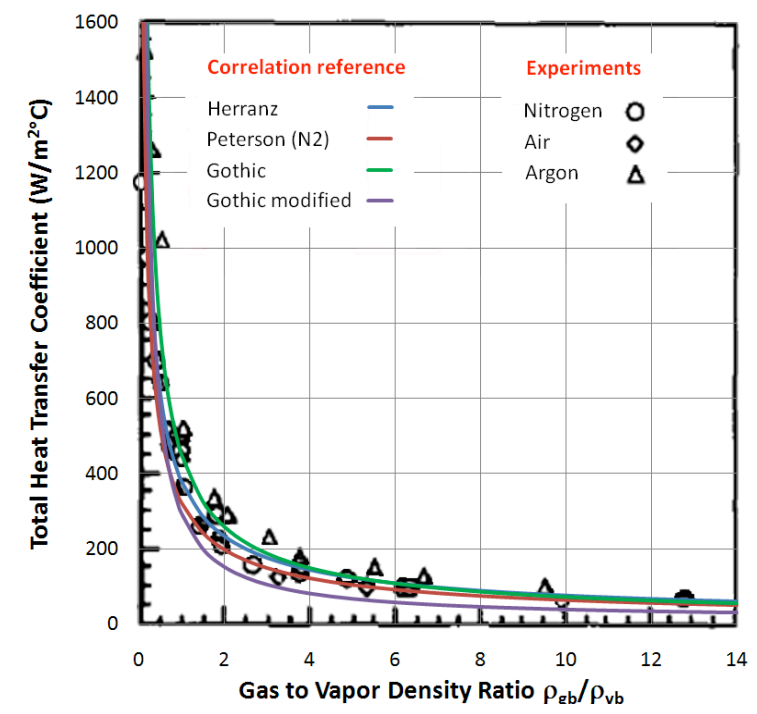

Table 1: List of the various formulations of Uchida correlation for condensation of steam inside containments.

\begin{tabular}{ll}
\hline \multicolumn{1}{c}{ Condensation HTC - Uchida correlation } \\
\hline$h_{\text {Uchida }}=380\left(\frac{W}{1-W}\right)^{-0.7}$ & Herranz reference \\
$h_{\text {Uchida }}=323\left(\frac{\rho_{g b}}{\rho_{v b}}\right)^{-0.7}$ & Peterson reference \\
$h_{\text {Uchida }}=450.44\left(\frac{\rho_{g b}}{\rho_{v b}}\right)^{-0.8}$ & GOTHIC Uchida \\
$h_{\text {Uchida }}=11.36+283.90\left(\frac{\rho_{g b}}{\rho_{v b}}\right)^{-1}$ & $\begin{array}{l}\text { GOTHIC } \\
\text { modified Uchida }\end{array}$ \\
\hline
\end{tabular}

Figure 1: Uchida experimental data adapted from [9] and compared with the various relationships developed. 
Figure 1 shows the comparison of the different formulations with Uchida experimental data (obtained with the three non-condensable gases nitrogen, air and argon). With the main purpose of an advice to GOTHIC users, it is noticed that GOTHIC Uchida selection, qualified for its utilization in the code, gives slightly higher values in comparison with literature formulations. Modified Uchida selection, which has not been applied yet in the qualification of GOTHIC, but has been already used in Japan for containment applications [8], proves to be more conservative and closer to the experimental data collected with nitrogen. Both the formulations have been taken into the proper account for the case under examination.

\section{NODALIZATIONS OF THE IRIS DRYWELL}

IRIS safety strategy in response to a SBLOCA event, based on maintaining reactor coolant inventory rather than injecting makeup water, is accomplished thanks to its specific containment design. Pressure suppression capability is implemented hosting tanks with water (Pressure Suppression System -PSS-) and important safety features are provided with Longterm Gravity Makeup System (LGMS) and Automatic Depressurization System (ADS). Water inventory is kept in the core using combination of initial high containment backpressure, direct removal of the heat from the core and fast primary pressure decrease in the first phase of the transient, as well as direct heat removal from the core and addition of the water to the core from LGMS and from Reactor Cavity (RC) in the second phase of the transient. It is just mentioned that real modelling of IRIS containment is more complicated than presented model used to explore possible differences between the two codes applied to the calculation of the selected component.

Just the drywell region, as a largest volume in a calculational model, has been modelled within the containment. The goal of the simulation was to cover first $1000 \mathrm{~s}$ of the transient (blowdown phase), before pressure equalization and without ADS intervention. A double ended guillotine break is assumed, hence both side of the break (Reactor Vessel -RV- side and DVI side) are considered as mass and energy source to the drywell. Investigated drywell model is uncoupled from the rest of the containment model (RC, PSS, LGMS tanks) and

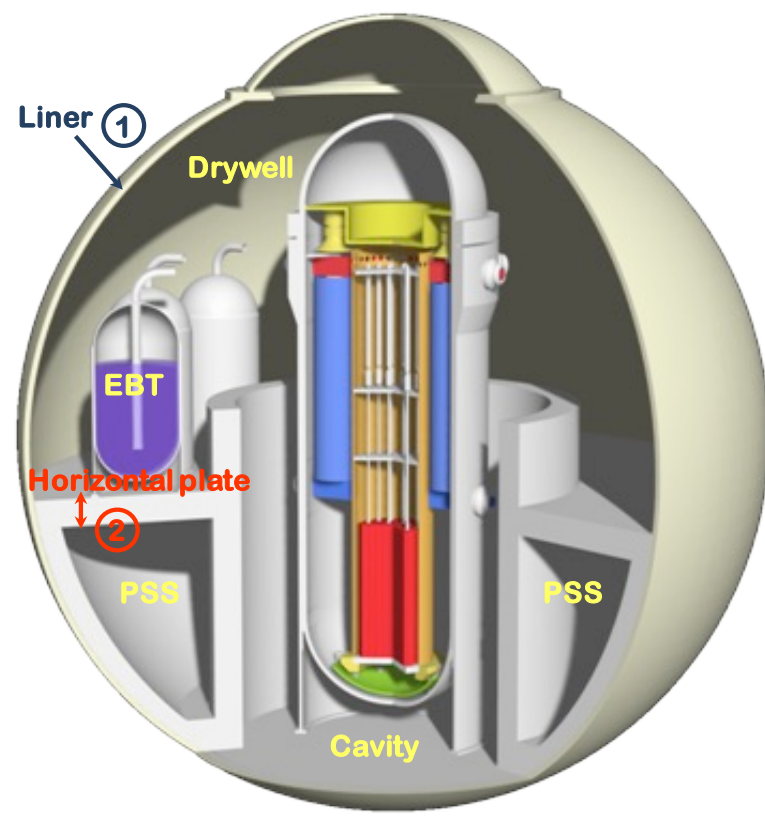

Figure 2: Drawing of the IRIS containment, showing the modelled heat structures.
Table 2: IRIS preliminary containment data.

\begin{tabular}{lc}
\hline Drywell & \\
\hline Volume $\left[\mathrm{m}^{3}\right]$ & 3227 \\
Height $[\mathrm{m}]$ & 11.5 \\
Hydraulic diameter $[\mathrm{m}]$ & 13.4 \\
Initial pressure $[\mathrm{Pa}]$ & $1.01325 \cdot 10^{5}$ \\
Initial temperature $\left[{ }^{\circ} \mathrm{C}\right]$ & 48.9 \\
Initial gas composition & $100 \% \mathrm{~N}_{2}$ \\
\hline Containment heat structures & \\
\hline Liner $(1)$ & Carbon Steel \\
Material & 0.0445 \\
Thickness [m] & 1005 \\
Surface $\left[\mathrm{m}^{2}\right]$ & \\
Horizontal plate $(2)$ & Concrete \\
Material & 0.30 \\
Thickness [m] & 252 \\
Surface [m ${ }^{2}$ ] & \\
\hline Environment & $1.01325 \cdot 10^{5}$ \\
\hline Initial pressure $[\mathrm{Pa}]$ & 35 \\
Initial temperature $\left[{ }^{\circ} \mathrm{C}\right]$ & \\
\hline
\end{tabular}


reactor vessel. The mass and energy releases from the reactor vessel, calculated by coupled RELAP/GOTHIC IRIS model, are simply represented as proper boundary conditions at the connection between drywell and reactor cavity.

The spherical geometry of the containment is simplified with a rectangular shape drywell with approximate free volume, according to the geometrical data reported in Table 2 . Two thermal structures are introduced to model the heat transfer from containment atmosphere to the containment wall and then to the external environment and from containment atmosphere to the operating deck concrete. The first heat structure is carbon steel liner wrapping the drywell, while the second heat structure is operating deck concrete dividing drywell volume from PSS tanks and rest of the containment, as clearly depicted in Figure 2. Liner thermal structure connects drywell volumes to the environment (AB building), modelling condensation and convection heat transfer within the drywell (internal side) and natural convection heat transfer towards the ambient (external side).

RELAP5 and GOTHIC codes have been used to build the described test model of the IRIS drywell, imposing the same boundary conditions and the same amount of heat structures.

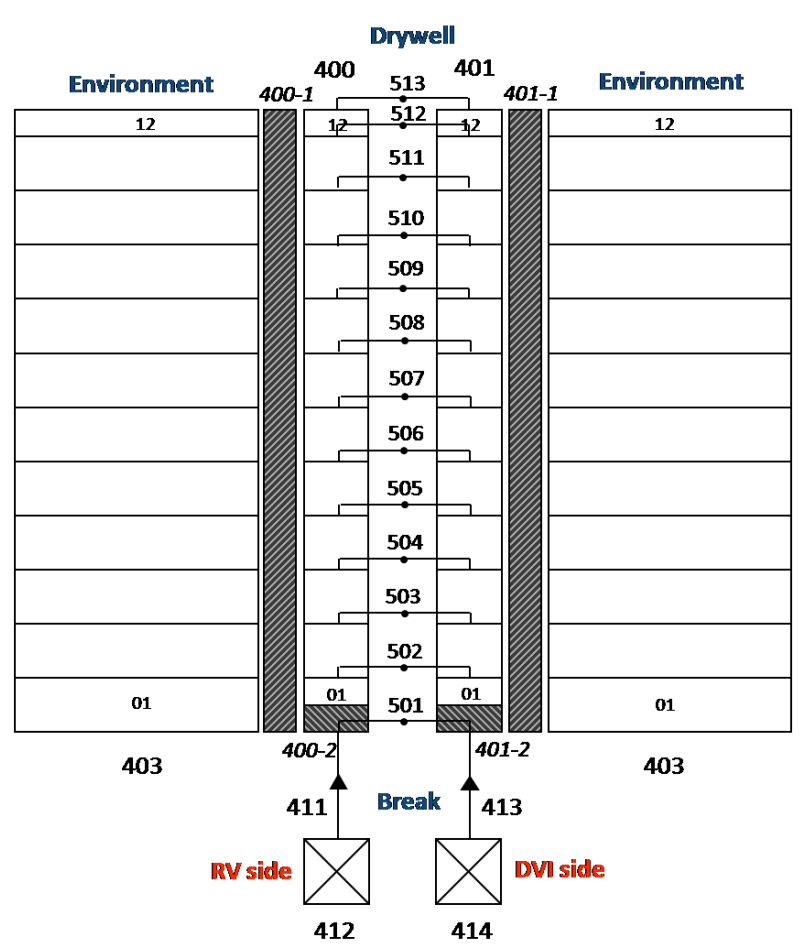

(a)

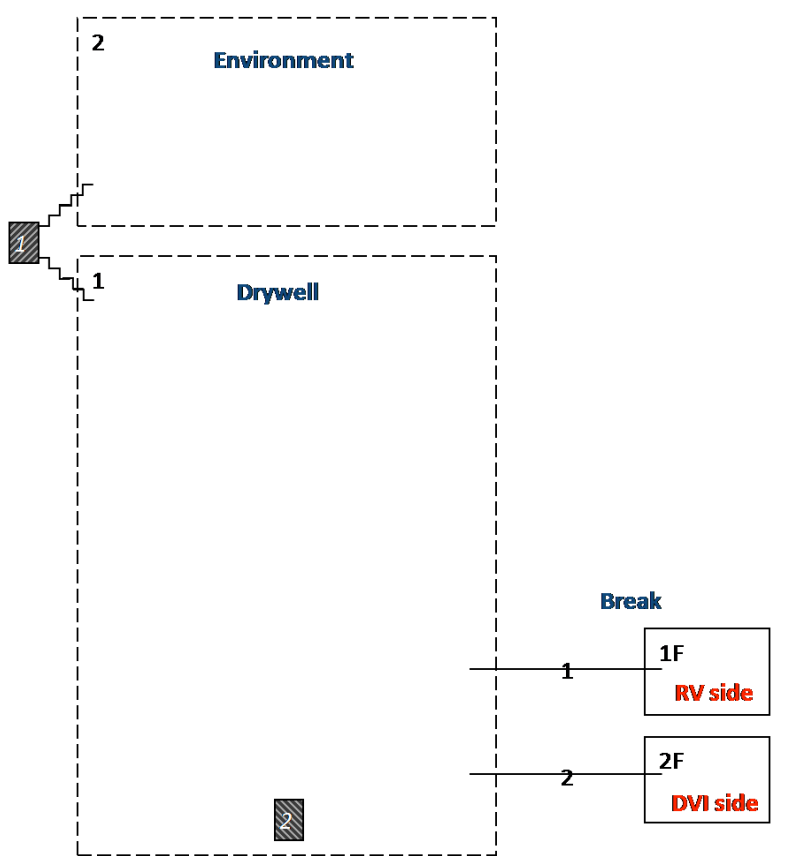

(b)

Figure 3: IRIS containment nodalization for the RELAP5 code (a) and for the GOTHIC code (b).

\subsection{RELAP5 nodalization}

Modelling of large components with the RELAP5 code is not an easy task. A sliced approach is used in order to better address atmosphere natural circulation flows. This approach is presented in Figure 3-a, where the developed nodalization is shown.

Drywell is simulated with two parallel pipes (400 and 401) subdivided in 12 volumes and connected by transversal single junctions. Heat structures representing carbon steel liner (400-1, 401-1), each for the competing portion of drywell pipes, are thermally coupled to the common environment, simulated with third RELAP pipe component (403). Heat structures representing concrete horizontal plate (400-2, 401-2) are connected from both sides (left and right bound) to the first volume of the two pipes. Break terms are employed as boundary conditions, by means of time-dependent junctions as regard mass flowrates, and timedependent volumes as regard break enthalpies (internal energies). 


\subsection{GOTHIC nodalization}

The IRIS drywell model developed with GOTHIC code has been built gradually, starting from a lumped volume approach, as depicted in Figure 3-b. Capability to model some recirculation within containment drywell is required, to address e.g. initial displacement of non-condesables to PSS tanks in real modelling of IRIS containment, and even most simple GOTHIC model of the drywell assumes at least two volumes for drywell representation. A more realistic simulation is based on a subdivided volume noding, closer to the RELAP sliced model given by 1D components. GOTHIC drywell volume is comprised thus of 64 subvolumes (4 axial levels, provided with a square matrix $4 \times 4$ each one), as shown in the two views of Figure 4. It should be mentioned that in both, RELAP sliced 1D approach with lateral flows and GOTHIC 3D subdivided approach, approximate height of the drywell is kept, but empty homogenous volume is assumed with all lateral dimensions determined according to considered free drywell volume. That means there are no pressure losses modelled in RELAP lateral junctions and there are no obstructions or porosity fractions taken into account in GOTHIC 3D volume. As far as GOTHIC heat structure modelling is concerned, a preliminary concentrated thermal structure nodalization has been improved into a multi-node concept.

Concentrated heat structure approach, depicted in Figure 4, deals with two spanned thermal conductors, shared over a rectangular group of contiguous cells and simulating respectively steel liner (top) and operating deck concrete (bottom). More realistic heat structures are obtained following a distributed scheme, where the external spanned conductor, modelling containment liner and previously attached just to top slice, is subdivided in more conductors, surrounding completely the subdivided drywell volume (Figure 5). Side heat transfer can be hence properly accounted, reproducing local effects and distinguishing
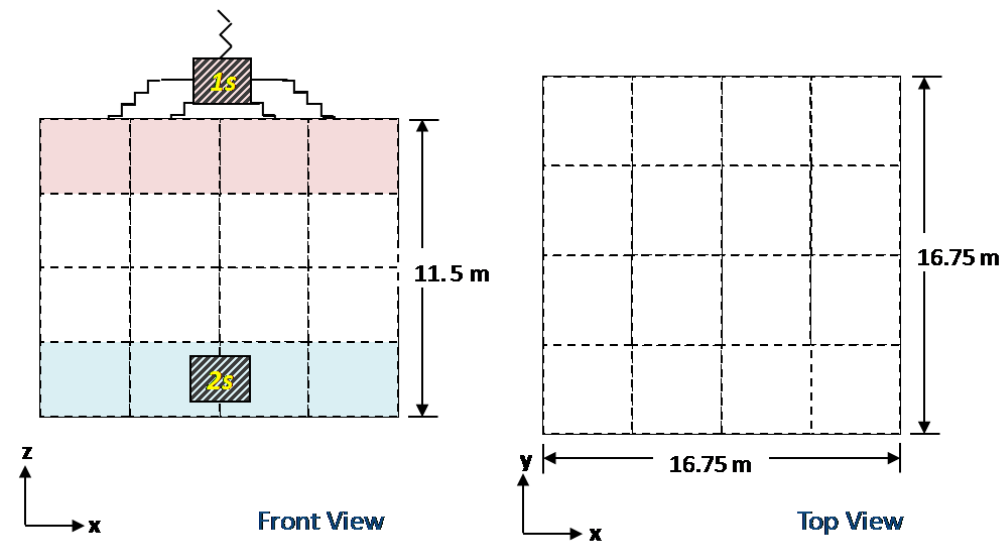

Figure 4: IRIS drywell nodalization for the GOTHIC code: concentrated thermal conductor approach.

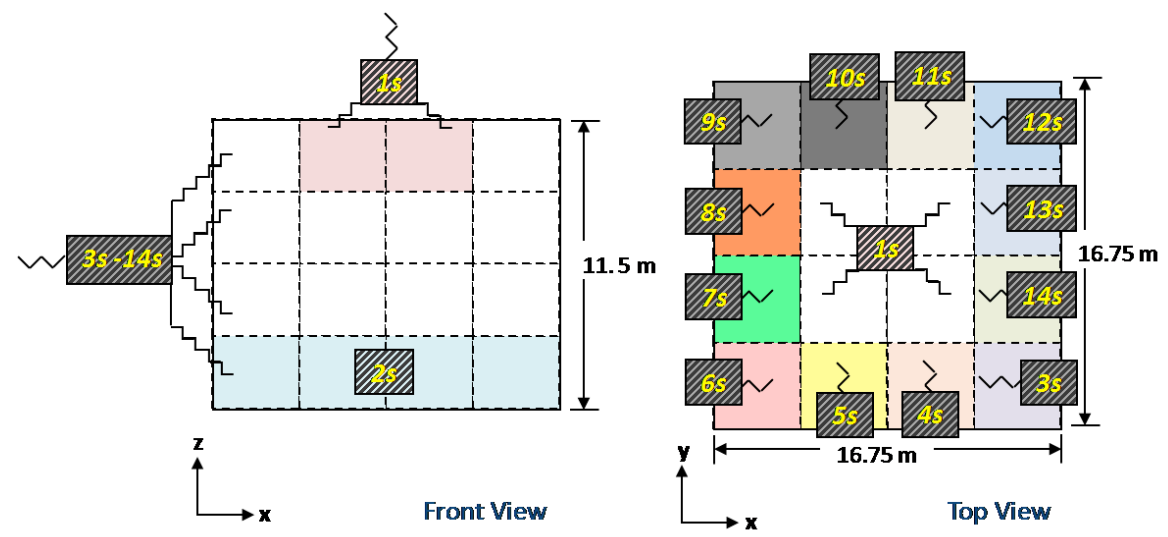

Figure 5: IRIS drywell nodalization for the GOTHIC code: distributed thermal conductor approach. 
between how steam condensation is provided at the top of the drywell and on its lateral walls. Natural convection is handled in different ways for vertical and horizontal part of the structures too.

Break terms are again employed as boundary conditions, linked to drywell volume with the respective flow paths. Break pressure, temperature, flow and liquid fraction (both for RV side and DVI side) dependence with time is provided with suitable forcing functions.

\section{RESULTS}

\subsection{Preliminary comparison between GOTHIC and RELAP5 models}

The results obtained with RELAP5 nodalization of IRIS drywell and with preliminary GOTHIC model, based on a subdivided volume with attached concentrated heat structures, are discussed in this Section.

The multi-volume nodalization allows in GOTHIC a better reconstruction of the accident progression, reproducing possible local 3D effects of internal recirculating flows and thermal stratification within the steam released. The condensation options presented in Section 2 have been compared, and the different HTCs predicted are shown in Figure 6-a. Gido-Koestel correlation displays a strong non-conservative peak at the beginning of the transient, being moreover not NRC approved. The influence on containment response of the different HTCs calculated is presented in Figure 6-b in terms of drywell temperature, which is a good representative parameter, being the most important signal of energy release within containment atmosphere. Uchida correlation, in particular with its modified version, predicts the highest peak and this conservative feature confirms its applicability to IRIS safety analyses.

Figure 6 shows also the results given by RELAP calculations. Just the HTC value predicted by heat structures connected to the $12^{\text {th }}$ volume of drywell pipes is provided. The values predicted in lower volumes are unrealistically high due to large lateral flows. Break source insertion causes a great disturbance in the lower part of drywell nodalization, making heat transfer rate calculation not reliable. The main reason can be found in the big overprediction of recirculation phenomena, as it is evident when comparing the recirculating mass flowrates assessed by GOTHIC CFD-like model (Figure 7-a) with those assessed by RELAP lateral junctions (Figure 7-b). The lower internal natural circulation is calculated for the higher drywell elevations, but the prediction is still one order of magnitude bigger than GOTHIC results.
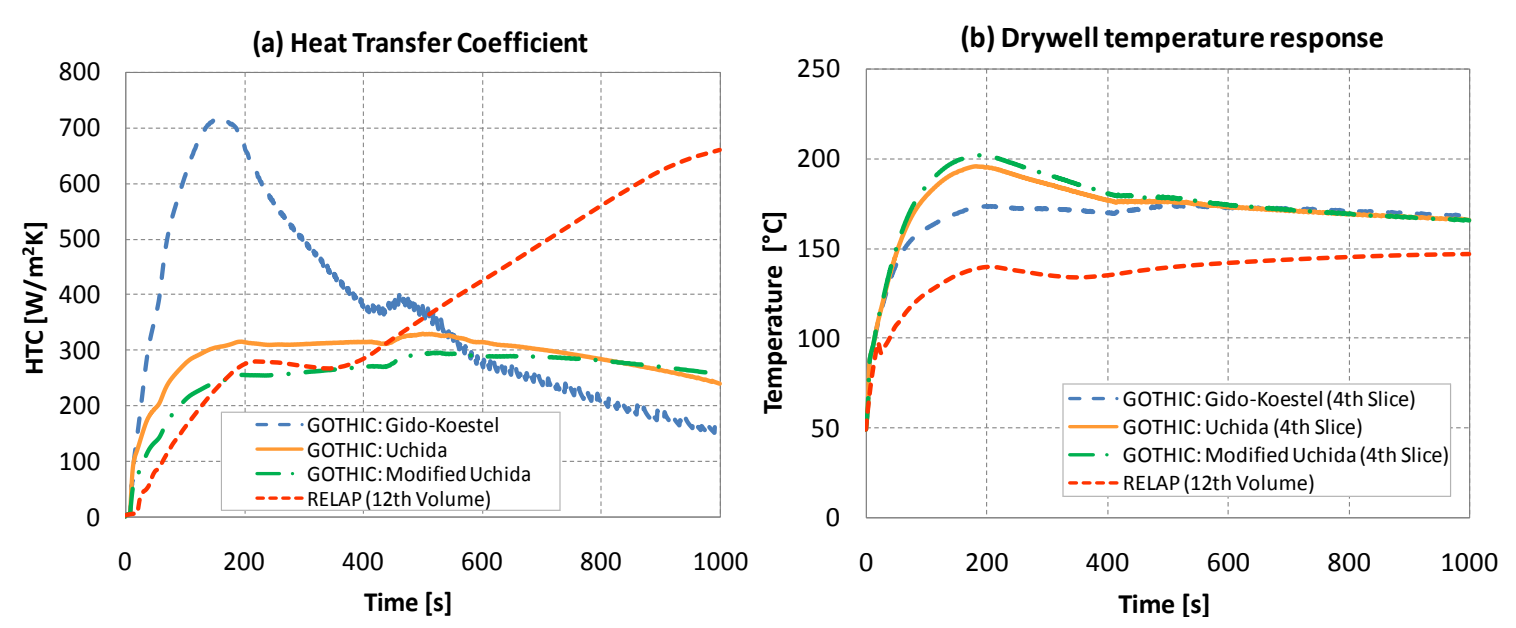

Figure 6: Total HTC (a) and drywell temperature (b) as predicted with GOTHIC preliminary model and by RELAP5 code. 

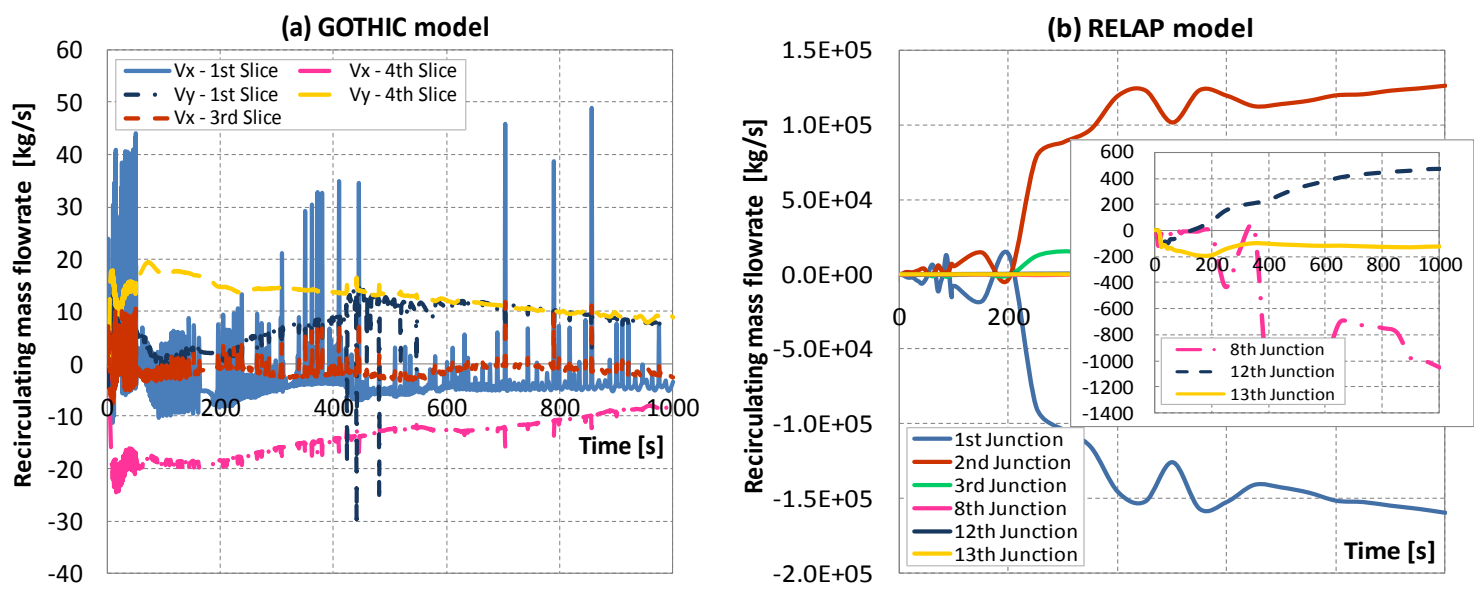

Figure 7: Internal natural circulation flows as predicted by GOTHIC (a) and RELAP5 (b).

The comparison of the temperature responses finally shows that steam superheating is predicted with GOTHIC, whereas the release of saturated steam is calculated with RELAP (temperature transient fits drywell pressure response).

\subsection{Presence of the droplets in GOTHIC break flow}

Several sensitivity studies have been provided through the GOTHIC model, investigating the influence of different parameters such as the natural convection contribution to the heat transfer and the relative humidity of drywell atmosphere. The most influencing action on system response prediction was found to be the activation of droplets presence in a fluid delivered by GOTHIC flow boundary conditions (simulating flow coming from the cavity after DVI break opening). The complete conversion of the liquid flow into droplets of the specified size is assumed.

The presence of the droplets during the reactor vessel blowdown increases heat exchange surface between discharged fluid and containment atmosphere, turning into a higher evaporation rate and an increase in containment pressure. More heat is taken for evaporating the liquid, hence a reduction of containment temperature increase occurs. A larger steam condensation is driven by the larger evaporation, influencing system behaviour on the long term. These effects are evident in Figure 8, where a sensitivity study on the considered Droplets Diameter (DD) is provided.

The most important consequence given by the activation of the droplets presence in flow boundary conditions is the cancellation of steam superheating within containment atmosphere. The droplets presence in discharged fluid during blowdown phase of the transient
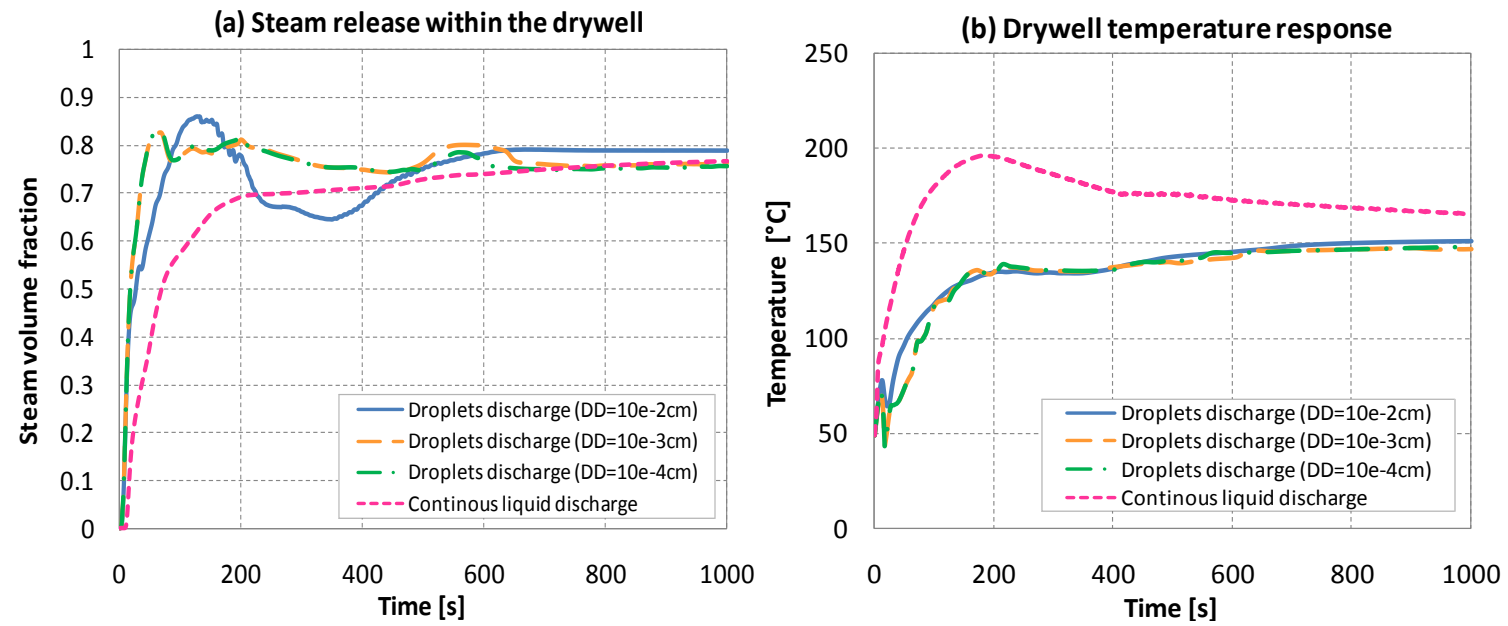

Figure 8: Effects of the droplets discharge model on the production of steam (a) and on drywell temperature response (b).

Proceedings of the International Conference Nuclear Energy for New Europe, Bled, Slovenia, Sept. 14-17, 2009 
is usual assumption adopted in classical licensing containment calculations.

\subsection{More realistic containment model developed with GOTHIC code}

In this Section the most important results obtained with the multi-node concept applied to GOTHIC thermal conductor simulating drywell liner are discussed. The option to introduce break discharge in form of droplets is considered.

Distributed heat structures permit to reproduce local effects of the condensation process, discriminating the various zones of the drywell. HTC distribution is shown in Figure 9-a, depicting several heterogeneities among the different sides of the containment. It is mainly evident how a concentrated thermal conductor attached to the top of the drywell is not in position to predict the heat transfer peak establishing on the lateral walls at the beginning of the transient. The differences are due to different convection parts of the heat transfer coefficient and to different non-condensable gas fractions. According to the higher transfer rates, containment pressure peak is noticeably reduced following the distributed heat structure approach. Such more realistic containment model predicts a pressure peak about 0.5 bar lower than preliminary model with steel heat structures connected just at the top of the model, as shown in Figure 9-b.

Notwithstanding the various shortcomings highlighted in Section 4.1, Figure 9-b shows also that RELAP code is capable of matching satisfactorily GOTHIC model predictions on containment pressure response.
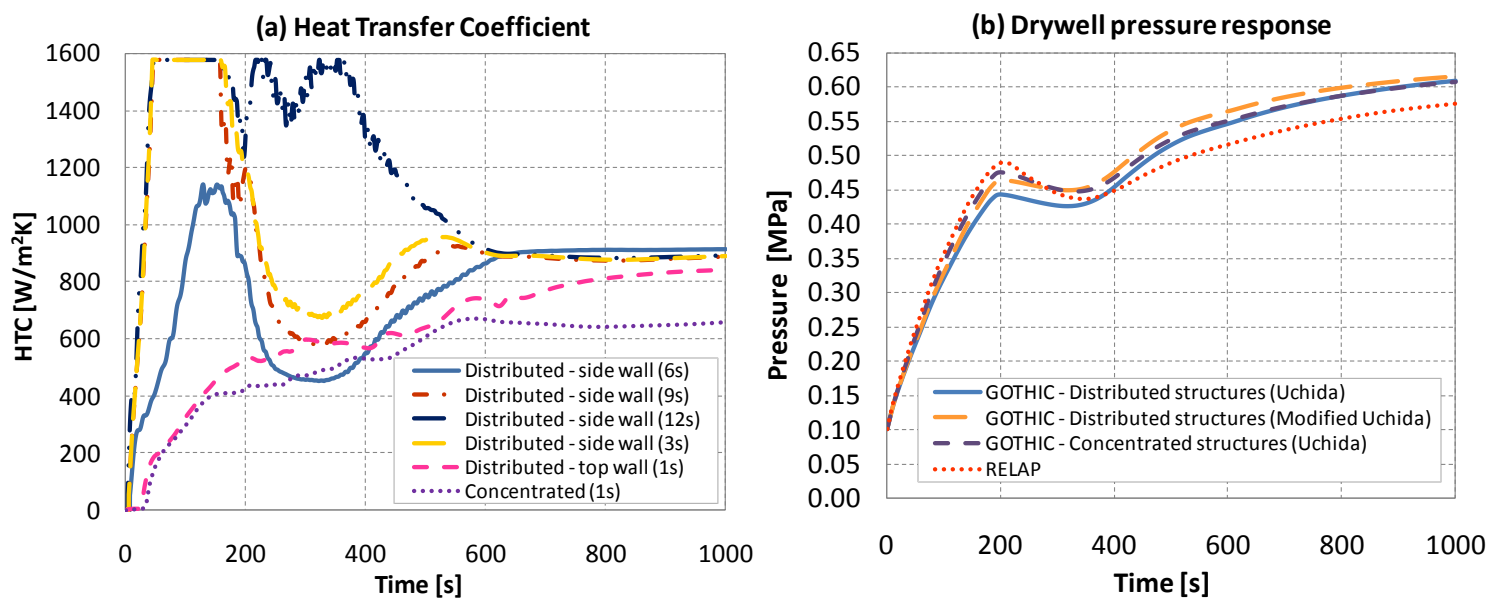

Figure 9: Total HTC (a) and drywell pressure (b) as predicted with GOTHIC more realistic containment model.

\section{CONCLUSIONS}

Several issues concerning IRIS containment modelling for a SBLOCA transient have been analyzed with the two codes GOTHIC and RELAP5. The same boundary conditions (break and mass energy sources) and the same amount of heat structures have been applied to a simplified model of the drywell alone, in order to quantify how the utilization of different codes with different heat transfer packages for steam condensation could get similar predictions on the same postulated accident. The modelling of IRIS drywell with GOTHIC and RELAP codes has also been presented in this paper.

The key parameter influencing condensation of the steam released has been indicated in the amount of non-condensable gas present within the containment. The empirical Uchida correlation has been identified to better model this effect under IRIS containment conditions. GOTHIC heat transfer package offers also a modified version of Uchida correlation, which looks promising for its more conservative behaviour. RELAP used the entire time default heat transfer correlation package with film condensation taken into account. 
A good qualitative agreement has been obtained between GOTHIC and RELAP predictions on IRIS drywell response. Though internal natural circulation was remarkably overestimated by RELAP, its diffusion method for dealing with condensation phenomena in presence of non-condensable showed to be adequate to match Uchida predictions obtained with GOTHIC. RELAP containment two-pipe-with-junction model with proper choice of lateral junctions can be hence considered as an acceptable tool for addressing large volumes in transient analyses. That conclusion can help in finding explanations for differences when comparing IRIS coupled code calculations and SPES3 RELAP calculations performed during design verification of SPES3 facility.

The option to include droplets in break flow boundary conditions is the most influencing parameter for GOTHIC simulations (from point of view of predicting drywell pressure and temperature). The higher evaporation rate causes an increase in containment pressure and a reduction in temperature due to the larger condensation rate. This leads to the elimination of steam superheating, as expected from the RELAP5 calculations on the test facility SPES3. Distributed heat structures attached to subdivided 3D volume permitted finally a more physical representation of IRIS drywell, predicting more realistic condensation HTC distribution and pressure peak estimation.

\section{REFERENCES}

[1] M.D. Carelli, L.E. Conway, L. Oriani, B. Petrović, C.V. Lombardi, M.E. Ricotti, A.C.O. Barroso, J.M. Collado, L. Cinotti, N.E. Todreas, D. Grgić, M.M. Moraes, R.D. Boroughs, H. Ninokata, D.T. Ingersoll, F. Oriolo, "The design and safety features of the IRIS reactor", Nucl. Eng. Des., 230, 2004, pp. 151-167.

[2] M. Carelli, L. Conway, M. Dzodzo, A. Maioli, L. Oriani, G. Storrick, B. Petrović, A. Achilli, G. Cattadori, C. Congiu, R. Ferri, M. Ricotti, D. Papini, F. Bianchi, P. Meloni, S. Monti, F. Berra, D. Grgić, G. Yoder, A. Alemberti, "The SPES3 experimental facility design for the IRIS reactor simulation", Science and Technology of Nuclear Installations, vol. 2009, Article ID 579430, 2009, 12 pages.

[3] D. Grgić, L. Oriani, L.E. Conway, "Development Status and Preliminary Validation of a Coupled RELAP/GOTHIC Code for IRIS Small Break LOCA Analysis", Proc. Int. Conf. on Nuclear Option in Countries with Small and Medium Electricity Grids, Dubrovnik, Croatia, May 16-20, 2004.

[4] A. Del Nevo, A. Manfredini, F. Oriolo, S. Paci, L. Oriani, "Integrated analysis for a Small Break LOCA in the IRIS reactor using MELCOR and RELAP5 codes", Proc. Int. Conf. on Nuclear Option in Countries with Small and Medium Electricity Grids, Dubrovnik, Croatia, May 16-20, 2004.

[5] J.C. Collier, Convective Boiling and Condensation, McGraw-Hill, New York, 1981.

[6] L.E. Herranz, M.H. Anderson, M.L. Corradini, "A diffusion layer model for steam condensation within the AP600 containment", Nucl. Eng. Des., 183, 1998, pp. 133-150.

[7] A. Ganguli, A.G. Patel, N.K. Maheshwari, A.B. Pandit, "Theoretical modeling of condensation of steam outside different vertical geometries (tube, flat plates) in the presence of noncondensable gases like air and helium", Nucl. Eng. Des., 238, 2008, pp. $2328-2340$

[8] GOTHIC Containment Analysis Package: Technical Manual, NAI 8907-06 Rev16, 2005.

[9] P.F. Peterson, "Theoretical basis for the Uchida correlation for condensation in reactor containments", Nucl. Eng. Des., 162, 1996, pp. 301-306. 